This document is the author's post-print version of this article, i.e. the final draft version after review. The final document is available in Building and Environment and can be viewed online by using the DOI 10.1016/j.buildenv.2013.05.026.

We also refer to this URL for citing details.

Li, W.Z., Van den Bulcke, J., De Windt, I., Van Loo, D., Dierick, M., Brabant, L., Van Acker, J. (2013). Combining electrical resistance and 3-D X-ray computed tomography for moisture distribution measurements in wood products exposed in dynamic moisture conditions. Building and Environment 67: $250-259$. 


\title{
Combining electrical resistance and 3-D X-ray computed tomography for moisture distribution measurements in wood products exposed in dynamic moisture conditions
}

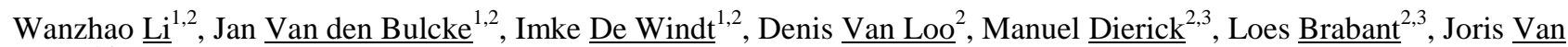
$\underline{\text { Acker }}^{1,2}$

${ }^{1}$ Ghent University, Department of Forest and Water Management, Faculty of Bioscience Engineering, Coupure Links 653, 9000 Gent, Belgium, Wanzhao.Li@UGent.be

${ }^{2}$ UGCT, University Ghent Centre for X-ray Tomography, Proeftuinstraat 86, 9000 Ghent, Belgium

${ }^{3}$ Ghent University, Department of Physics and Astronomy, Institute for Nuclear Sciences, Proeftuinstraat 86, 9000 Ghent, Belgium

\begin{abstract}
Strength and durability of wood-based products are substantially influenced by moisture. It is, therefore, crucial to monitor the moisture content (MC) distribution in wood products to fully understand their behaviour in dynamic moisture conditions. In this paper, we present a combined X-ray CT method and an adapted version of the electrical resistance MC measurement method for detailed studies on MC distribution in wood products. The X-ray CT method is evaluated using the gravimetrically recorded MC of solid wood. Subsequently, the recorded MC of electrical method is evaluated by using X-ray CT method. Three wood products are used for this purpose, i.e. solid wood, plywood and oriented strand board (OSB) panels. It is proven that X-ray CT method can accurately determine the MC of wood products and thus has great potential for non-destructively measuring the MC distribution in 3D. Furthermore, the results show that electrical method can effectively record the local MC when the MC distribution in this region is even. Otherwise, the position of the electrodes, with regard to specific wood properties has a substantial influence on its performance. Compared with solid wood and OSB, the electrical method performs best in plywood due to its layered structure. The adapted electrical method is an effective tool for continuously monitoring the MC distribution of wood products, taking into account that the electrodes are installed correctly according to the structure of the material and research questions. Combined with X-ray CT scanning, MC distribution of wood-based products under in-service applications, can be monitored.
\end{abstract}

\section{Keywords: Electrical resistance; X-ray computed tomography; Moisture content; Wood structure}

\section{Introduction}

Wood is increasingly used as a construction material in the building industry because of its sustainability, renewability and flexible usability. However, as a natural material, wood is prone to attack by fungi when water is available and environmental conditions favour growth. The optimal condition for decay by the most active white and brown rot fungi is the moisture content (MC) above fibre saturation point (FSP). The MC of wood, therefore, is usually considered as the key factor that determines whether or not fungi can grow, and thereby wood rot can occur [1]. It is well known that the MC also has an important influence on the physical and mechanical properties of wood based materials [2]. Hence it is crucial to monitor MC when wood is used outdoors to better understand its behaviour when subjected to dynamic outdoor conditions with possible liquid water ingress. Previous study by Van den Bulcke and co-workers [3] introduced the CMM method, with continuously weighing of plywood exposed outdoors for calculation of the average MC of the samples. Moisture distribution is a key factor as well. To further monitor this distribution, one could cut the samples into small sections, weighing them individually to reconstruct the moisture distribution [4], yet this technique is obviously a destructive one, hindering long-term recording. The electrical resistance method is another method to continuously record moisture, being non-destructive and reasonably accurate. Long-term electrical measuring $\mathrm{MC}$ of rather large samples, made of pine, spruce and fir, has been tested before as a feasible approach [5,6]. More advanced techniques exist as well. Magnetic resonance imaging is a non-destructive modality that has been used too as a tool for monitoring the free water movement in wood and wood-based products [7, 8]. Other researchers [9, 10] have proven that X-ray scanning, also as a non-destructive approach, could efficiently reveal density distributions in wood products and wood-based composites. There is a linear relationship between CT number and density of wood containing both wood substance and water [11]. According to the density in different positions of the wood, moisture distribution was further derived from these scans $[12,13]$. Neutron imaging is similar to X-ray methods but not as common as the latter. It was also used to test wood density and moisture in previous studies [14, 15]. 
Clearly many approaches have been applied for monitoring the MC content and distribution of wood products, but there is not a single method that can simultaneously monitor accurately, continuously and nondestructively the MC distribution in dynamic moisture conditions. Hence, in this research, an X-ray CT method was searched for to accurately map the MC distribution of wood products in three dimensions. This method was then used to evaluate whether an adapted version of the electrical resistance measurement as described by Brischke et al. [5] can be the preferred non-destructive and effective method to continuously monitor the water distribution in different wood species and wood-based panels. Several specimens of solid wood, plywood and OSB were immersed in water for 16 days (384 hours). All specimens were scanned on a regular basis with high-throughput X-ray CT to link the actual local MC inside the specimens and the MC as recorded with the electrical resistance measurements. Furthermore, the relationship between the microstructure of the specimens and the electrical MC measurement performance was analyzed using the volumetric X-ray data.

\section{Material and methods}

\subsection{Specimens without electrodes}

A set of specimens was used to assess the accuracy of X-ray CT method for moisture distribution monitoring. Solid wood specimens measuring $50 \times 50 \times 15 \mathrm{~mm}^{3}$, were prepared from four wood species: poplar (Populus spp.), Scots pine heartwood and sapwood (Pinus sylvestris) and birch (Betula spp.). All specimens were without decay, knots and obvious defects. The specimens were conditioned in a conditioning room at $65 \% \mathrm{RH}$ and $20^{\circ} \mathrm{C}$ until constant mass after which all specimens were weighed. The specimens were immersed for 48 hours in a container filled with demineralised water. During this period, the specimens were weighed and scanned after $0,1,4,8,24,48$, hours of immersion. After 48 hours of immersion, the specimens were oven-dried, weighed and scanned. With each scan also a plastic vial containing demineralised water was scanned along.

\subsection{Specimens with electrodes}

For evaluation of the electrical resistance method, solid wood specimens were prepared from six different wood species: poplar (Populus spp.), spruce heartwood (Picea abies), Scots pine heartwood and sapwood (Pinus sylvestris), okoumé (Aucoumea klaineana) and birch (Betula spp.), all measuring $70 \times 50 \times 15 \mathrm{~mm}^{3}$ and $50 \mathrm{~mm}$ along the grain direction. Also PF (phenol formaldehyde) glued plywood, and OSB panels with isocyanate glue, were prepared and sawn to the size of $70 \times 50 \times$ panel thickness $\mathrm{mm}^{3}$ (Table 1). All specimens were without decay, knots and obvious defects. Two holes of $4 \mathrm{~mm}$ diameter were drilled in the specimens. The distance between the centers of the holes was $30 \mathrm{~mm}$ orthogonal to the grain. Inside the 4 $\mathrm{mm}$ drill hole, another small hole with $1 \mathrm{~mm}$ diameter was drilled starting from the bottom of the former drill hole (Fig.1). Then, these specimens were conditioned in a conditioning room at $65 \% \mathrm{RH}$ and $20^{\circ} \mathrm{C}$ until constant mass after which all specimens were weighed. After weighing, all sides of the solid wood specimens except one end grain face (cross section) were sealed, while, for plywood and OSB panels, only four sides were sealed. This way, the water was allowed to enter the specimens in one direction only. Next, the wires were glued in the predrilled holes with conductive and isolating glue as described in Brischke et al. [5].

Table 1
These electrodes were made of stripped commercial wires. In order to avoid beam hardening and metal
artefacts in X-ray CT scanning, thick metal wires such as described in Brischke et al. [5], are not suitable.
Hence, wires with plastic cover having a diameter of $0.2 \mathrm{~mm}$ were used in this experiment. Furthermore, in
order to decrease possible noise, the following protocols had to be followed: the wires in the small holes at
the bottom of the large drill holes were fixed using conductive glue to make sure these electrodes could
effectively test the MC at the region of interest (further called ROI, see Fig.1). We assume that the
measurements are mainly influenced by the MC in this region. As is well known, water movement in wood
mainly takes place along the grain direction and the speed of movement is not identical for different wood
species. Hence, for solid wood, the distance (X) between end grain face and the electrodes is different
according to the anticipated absorption of the different wood species (Fig.2). These distances are listed in
Table 2. All electrodes were positioned at the same depth, i.e. 7 mm from the top face. It is the aim of
electrical resistance method to measure the general MC distribution instead of accurate regional MC of
different wood products. Electrical loggers (Materialfox Mini), with the same formula to convert electrical
resistance to MC, were used for reading out the MC values of all specimens from different wood species.


The formula is specifically applied to calculate MC of pine and spruce species. We assume that the influence of wood species is rather small.

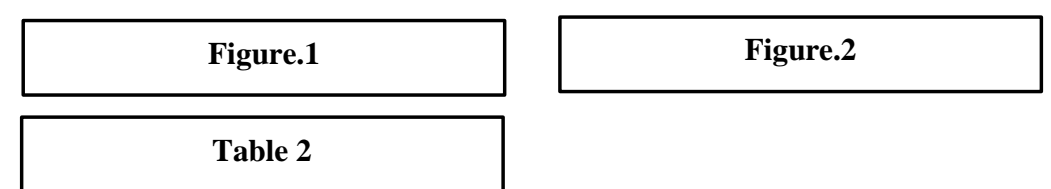

For plywood and OSB, two pairs' of electrodes were installed in each specimen at different depths to record the MC distribution in vertical direction (Fig. 3). The depths for each pair of electrodes are listed in Table 3 and were carefully controlled and adjusted if necessary using X-ray radiography.
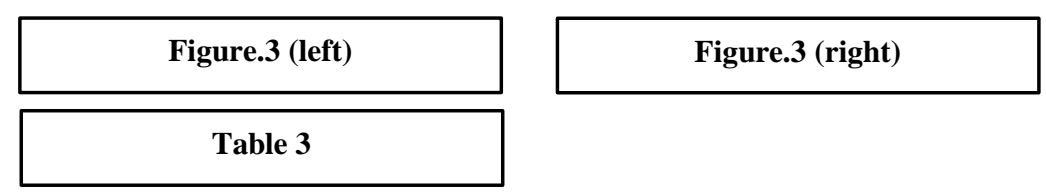

Finally, the specimens were conditioned again until constant mass and weighed. Subsequently they were positioned with the appropriate face / end grain in a container and immersed in demineralised water in the conditioning room. For plywood and OSB, the specimens were put in the container horizontally allowing water to move from the bottom face up. All specimens were mounted on stainless steel grids to avoid complete submersion and placed in the water for 16 days ( 384 hours). During this period, the electrical MC was recorded every 24 hours and the specimens were scanned after 0, 24, 48, 96, 168, 216, 264, 336, 384 hours of immersion. Electrical measurements were recorded after taking the specimens out of the water, blotting the immersed surface with tissue paper and storing the specimens for $30 \mathrm{~min}$ in a conditioning room to avoid incorrect measurements. .

\subsection{Gravimetrical method}

All specimens were weighed before scanning. The average MC could be obtained with following formula:

$M C_{x}^{\mathrm{i}}=\left(\mathrm{m}_{\mathrm{x}}^{\mathrm{i}}-\mathrm{m}_{0}^{\mathrm{i}}\right) / \mathrm{m}_{0}^{\mathrm{i}} \times 100$

The calculations are adjusted to correct for the weight of edge sealant and wires. The sealant and wires are considered having a constant weight and as such the average MC of the specimens could be calculated using the following equation:

$M C_{x}^{i}=\left(m_{x}^{i}-m_{0}^{i}\right) /\left[m_{0}^{i}-\left(m_{2}^{i}-m_{1}^{i}\right)\right] \times 100$

with $M C_{x}^{i}$ : the average moisture content of specimen $\mathrm{i}$ at time $\mathrm{x}(\%)$; $\mathrm{m}_{\mathrm{x}}^{\mathrm{i}}$ : the mass of specimen $\mathrm{i}$ at time $\mathrm{x}$ $(\mathrm{g}) ; \mathrm{m}_{1}^{\mathrm{i}}$ : the conditioned mass of specimen $\mathrm{i}$ with holes $(\mathrm{g}) ; \mathrm{m}_{2}^{\mathrm{i}}$ : the conditioned mass of specimen $\mathrm{i}$ with glue and wires $(\mathrm{g}) ; \mathrm{m}_{0}^{\mathrm{i}}$ : the oven-dry mass of specimen $\mathrm{i}(\mathrm{g})$.

\subsection{X-ray scanning}

All specimens were scanned with the CT scanning set-up built at the Ghent University Centre for X-ray Tomography (www.ugct.ugent.be). The scanner is similar to the one as described in Masschaele et al. [16] and used in Van den Bulcke et al. [17, 18]. It has a generic in-house developed CT scanner control software platform [19] that allows full control of the scanner hardware. The scan settings and test set-up were optimized to limit scan time to 6 minutes per specimen and avoid drying. 16 bit projection images were obtained. Reconstruction was performed with Octopus, a tomography reconstruction package for parallel, cone-beam and helical geometry [20]. An approximate voxel pitch of $100 \mu \mathrm{m}$ was obtained. Both hard- and software filtering was necessary to reduce the remaining metal artefacts.

\subsection{Data processing}

Converting greyscale values to actual MC is a non-trivial procedure. In X-ray absorption tomography the attenuation is dependent of the chemical composition of the specimen, the density of the material and the energy of the X-ray beam. The last is assumed equal for all experiments and thus not influencing the results. When a specimen consists of different constituents, the ratio of these constituents influences the attenuation 
coefficient. Hence their greyscale value, in this case of water and wood, should be obtained independently. The general relationship between a constituent and its greyscale value can be expressed as following:

$$
\begin{aligned}
& \mathrm{G}=\mu{ }^{\prime} \times \rho \\
& \mu^{\prime}{ }_{\text {wood }}=G_{\text {dry }} / \rho_{\text {dry }} \\
& \mu_{\text {water }}^{\prime}=G_{\mathrm{H} 2 \mathrm{O}} \times 1 \\
& G_{\text {sum }}=G_{\text {wood }}+G_{\text {water }} \\
& G_{\text {wood }}=\mu_{\text {wood }}^{\prime} \times \rho_{\text {wood }} \\
& G_{\text {water }}=\mu_{\text {water }}^{\prime} \times \rho_{\text {water }}
\end{aligned}
$$

with G: the average greyscale value of the material; $\mu$ ': the attenuation coefficient per unit mass of material $\left(\mathrm{cm}^{2} / \mathrm{g}\right) ; \rho$ : the material density $\left(\mathrm{g} / \mathrm{cm}^{3}\right) ; \mathrm{G}_{\mathrm{dry}}$ : the average greyscale value of oven-dried wood; $\rho_{\mathrm{dry}}$ : the density of oven-dried wood $\left(\mathrm{g} / \mathrm{cm}^{3}\right) ; \mathrm{G}_{\mathrm{H} 2 \mathrm{O}}$ : the average greyscale value of pure water; $\mathrm{G}_{\mathrm{sum}}$ : the total greyscale value of the material; $G_{\text {wood }}$ : the greyscale value of the wood; $G_{\text {water }}$ : the greyscale value of water; $\mu_{\text {wood: }}^{\prime}$ the mass attenuation coefficient of wood $\left(\mathrm{cm}^{2} / \mathrm{g}\right) ; \rho_{\text {wood }}$ : the partial density of wood substance $\left(\mathrm{g} / \mathrm{cm}^{3}\right)$; $\mu_{\text {water }}^{\prime}$ : the mass attenuation coefficient of water $\left(\mathrm{cm}^{2} / \mathrm{g}\right) ; \rho_{\text {water }}$ : the partial density of water $\left(\mathrm{g} / \mathrm{cm}^{3}\right)$.

As is well known, the standard gravimetrical MC is calculated by using Eq. (11). Measuring MC by application of X-ray CT method is, however, an indirect approach as the greyscale value is related to the density of wood and water rather than to the MC only. Hence, by substitution of Eq. (6), Eq. (7) and Eq. (8) into Eq. (11), the MC can be obtained using Eq. (12). The attenuation coefficient of $\mathrm{H}_{2} \mathrm{O}$ obtained by scanning pure demineralised water is assumed to be constant because the same $\mathrm{X}$-ray scanning setup was used for all specimens. The attenuation coefficient of wood is acquired by scanning the oven-dried specimens.

$$
\begin{aligned}
& \mathrm{G}_{\text {ROI-sum }}^{\mathrm{i}}=\mathrm{G}_{\text {ROI }}^{\mathrm{i}} \times \mathrm{V}_{\text {ROI }}^{\mathrm{i}} \\
& \mathrm{G}_{\text {ROI-sum }}^{\mathrm{d}}=\mathrm{G}_{\text {ROI }}^{\mathrm{d}} \times \mathrm{V}^{\mathrm{d}}{ }_{\text {ROI }} \\
& \mathrm{MC}^{\mathrm{i}}=\rho_{\text {water }} \times \mathrm{V}_{\text {ROI }}^{\mathrm{i}} /\left(\rho_{\text {wood }} \times \mathrm{V}_{\text {ROI }}^{\mathrm{i}}\right) \\
& \mathrm{MC}^{\mathrm{i}}=\left(\mathrm{G}_{\text {ROI-sum }}^{\mathrm{i}}-\mathrm{G}_{\text {ROI-sum }}^{\mathrm{d}}\right) \times \mu_{\text {ROI-wood }}^{\prime} \times 100 / \mathrm{G}_{\text {ROI-sum }}^{\mathrm{d}} \times \mu_{\text {water }}^{\prime}
\end{aligned}
$$

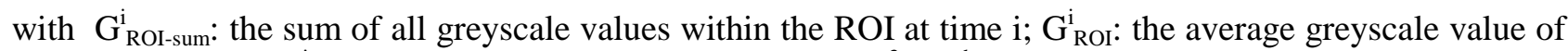
the ROI at time $\mathrm{i}$; $\mathrm{V}_{\text {ROI }}^{\mathrm{i}}$ : the volume of the ROI at time $\mathrm{i}\left(\mathrm{cm}^{3}\right) ; \mathrm{G}_{\text {ROI-sum }}^{\mathrm{d}}$ : the sum of the greyscale values of ROI of the oven-dried specimen; $G^{d}{ }_{\text {ROI }}$ : the average greyscale value of the ROI of the oven-dried specimen; $\mathrm{V}^{\mathrm{d}}{ }_{\text {ROI }}$ : the volume of the ROI of the oven-dried specimen $\left(\mathrm{cm}^{3}\right)$; $\mathrm{MC}^{\mathrm{i}}$ the moisture content of the ROI at time $\mathrm{i}(\%) ; \mu_{\text {ROI-wood: }}^{\prime}$ the mass attenuation coefficient of wood of the ROI $\left(\mathrm{cm}^{2} / \mathrm{g}\right)$.

The software package Morpho+ was used to obtain the average greyscale values of the different constituents [21]. Preprocessing of the volumes included bilateral filtering to remove noise and preserve edges. By plugging the average greyscale value of water, wet and dry wood in abovementioned formulae, the MC of a specimen can be calculated. For the scanned volumes of the specimens without wires, thresholding was applied to segment the specimen and to calculate the average greyscale value. The ROI in this case equals the entire specimen to enable comparison with the gravimetrically determined MC. The volume of the specimens, therefore, was derived from the amount of voxels the sample consists of. The density of ovendried specimens is acquired from dividing weight by volume. For the specimens with wires, the ROI was demarcated manually and MC was calculated within this specific region. In order to obtain the oven-dried density of this region, reconstructed volumes were converted to density values with Matlab, as a reference material with known density was included in each scan. By using the average greyscale value of this reference material and air (zero density), greyscale values of reconstructed specimens can be converted to densities [10].

\section{Results and discussion}




\subsection{Evaluating the MC determined with X-ray CT method}

The X-ray CT derived MC was obtained using Eq. (12). As the specimens were not edge sealed and had no electrodes, the gravimetrical MC was calculated according to Eq. (1). Fig.4 illustrates the strong linear relationship (0.994) between the X-ray CT method and gravimetrical MC. The slight difference between them was induced by the moisture adsorption and desorption during scanning as well as an imperfect segmentation of background and sample due to remaining beam hardening artefacts. It indicates that the Xray $\mathrm{CT}$ method can accurately monitor the $\mathrm{MC}$ and its distribution in specimens.

\section{Figure.4}

\subsection{Optimizing X-ray scanning of specimens with electrodes}

A first adaptation of the electrical resistance method is the thickness of the wires used. Fig.5 shows that thick wires cause serious beam hardening, especially between the two electrodes, which can influence the MC calculation in this region. Thin wires were used for this reason to minimize beam hardening and metal artefacts in X-ray scanning and a small hole was drilled at the bottom of the large hole, as explained in the Materials and Methods section (Fig.1). The small hole was filled with conductive glue in which the thin wire was installed, as such ensuring proper contact between the thin wire and the surrounding wood material and a proper measurement of the MC in the ROI.

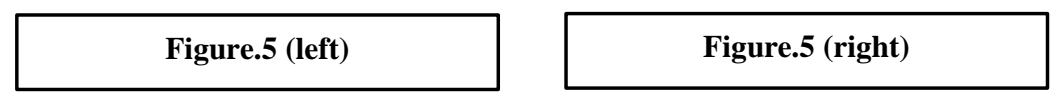

Wood swells and the volume of the specimens changes during water absorption. If an unchanged volume is used to calculate the MC, it might cause an incorrect estimation of the MC. However, due to the uneven swell in different areas, volume change of the entire specimen cannot represent the regional volume change. Therefore, three specimens were selected to investigate the relationship between entire and regional volume change. High density wood species have proportionately more cell wall and less lumen volume, thus shrink and swell more. Hence, the entire volume change of birch, obtained by recording the number of voxels of the entire specimen, is higher than for poplar (Fig.6). The volume change of plywood is small because the axial alignment of the fibers in one sheet of veneer restrains tangential movement in adjacent veneers [1]. As shown in Fig.6, the entire volume is larger than the ROI volume change. Therefore, the local volume was used to calculate MC of the ROI in between the electrodes. For solid wood and OSB, the volume of the ROI can be obtained from the distance between the two electrodes and the height of the small holes (Fig.1). For plywood, the volume is obtained from the distance of the two electrodes and the height from the bottom of the small hole to the nearest glue line. Swell along the grain is negligible, compared to that of other directions.

\section{Figure.6}

\subsection{MC of solid wood}

An example of X-ray CT scanning of a specimen with electrodes, illustrating the grey value distribution in the specimens as water is absorbed, is shown in Fig.7. In this experiment, since water is the only factor that causes the greyscale value to increase, these changes can be converted to MC changes. The highest MC is noted a few millimetres into the wood from the end grain surface as the water moves longitudinally into the specimens. The MC decreases with increasing distance from the end grain surface. The MC increases along with immersion time and obviously the edge region absorbs more water than the core. The moisture absorbed into the wood takes place due to the capillary force and presence of accessible hydroxyl groups when the MC is below the fibre saturation point (FSP). Above the FSP, free water moves into wood as a result of capillary forces [22,23]. This pressure force is related to a moisture and air gradient of nearby cells. Generally speaking, the air near the edge is easy to be forced out and consequently the air pressure gradient 
should be higher. Hence the water prefers to penetrate along with the edges. This result has also been found in spruce timber tested by Sandberg and Salin [13].

\section{Figure.7}

Fig.8 illustrates the water volume calculated by using X-ray MC in the ROI of several wood species. It is obvious that pine sapwood and birch absorb much more water than other wood species despite the fact that the distances between ROI and the end grain face are 40 and $35 \mathrm{~mm}$. On the other hand, pine heartwood, spruce and okoumé can effectively prohibit water from penetrating (Fig.8). Although poplar easily absorbs water, there is only a small amount of water in the ROI. This result is consistent with the MC profiles in Fig.7.

\section{Figure.8}

Fig.9 gives a graphical overview of the comparison of electrical and X-ray MC of the ROI as well as the average gravimetrical MC of the specimens. These results are obtained for different wood species. It is obvious that there is a substantial difference between the MC of the ROI and the average MC, which indicates that the average MC cannot represent the regional MC in dynamic moisture conditions. These results are consistent with the findings of Sandberg and Salin [13]. The MC for poplar determined with the electrical and X-ray method is equal except for the last measurements. In these last measurements, the increase of electrical MC is higher than X-ray MC, which means that the electrical resistance tested by the logger is smaller than the actual electrical resistance of the ROI. Reason for this phenomenon is that electricity follows the path of the least resistance rather than the shortest distance between two electrodes. From the MC profiles in Fig.7, there is no obvious water in the area between the two electrodes, while other positions are filled with water, as such making electricity flow around the ROI from which the X-ray derived MC is calculated. This explanation also holds for the last measurement of birch.
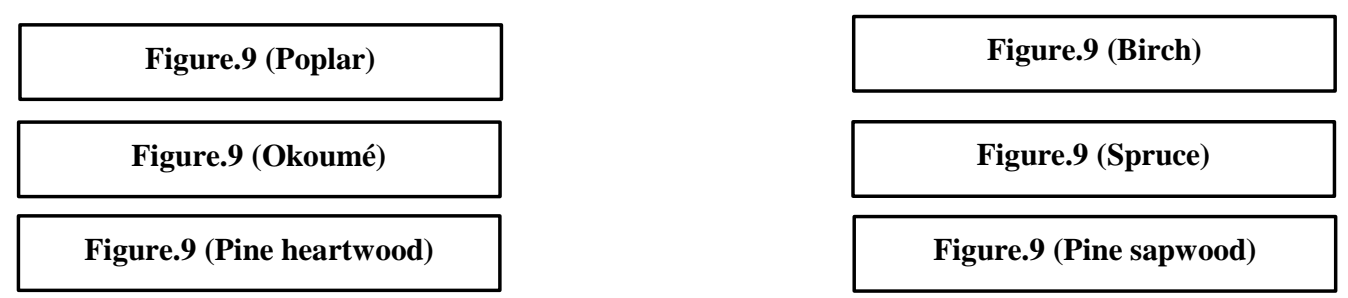

Fig.9 also shows that the X-ray MC is slightly higher than the electrical MC in spruce and pine heartwood. To explain this phenomenon, the macroscopic structure of these wood species is studied. Fig.10 shows the differences in density between the two electrodes of these wood species. The distinction of earlywood and latewood in softwood is obvious and much clearer for pine.

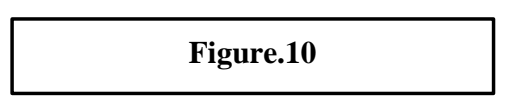

Latewood cells play a more significant role in water uptake than earlywood cells because latewood tracheids have smaller cell lumens. Hence water flows preferably along the latewood in longitudinal direction [24]. When there is free water in these cells, the structure of latewood cells, with smaller tracheids and thicker cell wall, can act as a boundary to free water movement [8]. Therefore, to prove if this characteristic would influence the MC distribution, the MC values of adjacent earlywood and latewood of pine heartwood (Fig.10a), from end grain face to the electrode are calculated. As shown in Fig.11 the MC of both earlywood and latewood is around $10 \%$ before immersion. After immersion, MC in latewood increases faster than in earlywood when the MC is below 30\% (FSP). Later on, obviously, most of the free water is found in the earlywood. The waterfront in Fig.11 also illustrates that water is absorbed from end grain face to the internal regions of the specimen and the decrease of the MC near the end grain face is caused due to drying during scanning, although scan time was shortened significantly by fine tuning the protocol. Because the electricity has to flow across latewood and earlywood and there is a negative relationship between MC 
and electrical resistance, the section with lower MC dominates the electrical resistance between two electrodes. Hence, the measured electrical MC is slightly smaller than the actual MC of ROI.

Figure.11 (Earlywood)

Figure.11 (Latewood)

As shown in Fig.9, the MC in the ROI of pine sapwood is higher than FSP at the first measurement. Based on above analysis, the MC of earlywood should be much higher than the MC of latewood, which would cause the electricity to flow along the earlywood. Hence, the measured electrical MC is higher than its real MC. Later on, due to the position of the electrodes and the wood structure of ROI, the electrical MC generally equals the actual MC of the ROI in the last measurements. For okoumé, there is no obvious latewood and earlywood (Fig.10d) demarcation and little absorbed moisture in ROI. The electrical MC measurement method, therefore, can effectively record the actual MC of ROI.

Similar electrical resistance MC measurements were performed by Brischke et al. [5, 6]. The structure of the wood did not influence their results as specimens were conditioned to equilibrium MC before measuring electrical MC or rather large specimens were used in outdoor conditions. Taking into account these conditions, the MC distribution in the core of the specimens is more or less even and the MC value of high and low density zone is close to each other when the MC is below FSP [25]. Therefore, the electrical MC is in a good agreement with the gravimetrical MC especially when the MC is below 30\% [5]. However, our experiments show that results can be heavily influenced by the absorption of liquid water; therefore electrical MC measurements should always be interpreted with proper knowledge of the material structure, including the specific anatomy and the position of the electrodes within the structure, especially when working with materials of much smaller dimensions, such as wood-based panels (cf. infra). Combining these measurements with X-ray tomography is an ideal situation.

\subsection{MC of plywood}

Plywood is an important engineered wood material in the building industry and therefore monitoring its water distribution is essential (e.g. [3]). Contrary to solid wood, the glue lines separate the veneers and hamper water movement between them. Fig.12 gives evidence that the gravimetrical average MC of the plywood specimens cannot be applied to evaluate the $\mathrm{MC}$ of the different layers. To investigate the moisture distribution, electrical and X-ray MC measurement methods are used for measuring the moisture distribution in each layer of the plywood. It should be noted that it is difficult to select exactly the same ROI in such a small volume for each scan, therefore, the results can show a slight up-and-down movement, although the general trend is clear. The slight fluctuations of the electrical MC can be caused by little remaining liquid water at the bottom face, decreasing the electrical resistance between the electrodes slightly. In Fig. 12b, 12c and $12 \mathrm{~d}$, the MC values as obtained with the electrical and X-ray method are comparable. However, Fig.12a shows that the electrical MC is much higher than X-ray MC when the MC exceeds $25 \%$. To explain this phenomenon, we take a closer look at the structure of plywood. Plywood is manufactured by gluing together veneers which are cut perpendicular to the grain with the knife parallel to the grain [1]. Hence, a single veneer can consist of both earlywood and latewood layers. As above analysis shows, water has a fast uptake by latewood when there is no free water whereas expressed in absolute values most of the free water is present in earlywood. Hence if the region with the electrodes contains earlywood and latewood layers, the electrical method might measure the MC of the layer with higher MC, with a smaller electrical resistance at that moment, while the X-ray method would measure the average MC of earlywood and latewood. Therefore, the recorded electrical MC is higher than the X-ray MC. On the contrary, if the electrodes are positioned in a region consisting of earlywood or latewood only, the electrical MC should be equal to the X-ray MC. This hypothesis is proven by the structure of spruce plywood in which the whiter region represents latewood and the darker region earlywood (Fig.13). As shown in Fig.13b, the region between the two electrodes in the $3^{\text {rd }}$ layer is basically entirely earlywood. Fig.13a shows that in the $2^{\text {nd }}$ layer, the electrodes just enter the earlywood layer then the electrical MC corresponds with the MC of the layer with higher MC. The water is absorbed from the bottom and has to penetrate the earlywood layer and then the latewood layer. Hence, the MC distribution is more or less even before free water gets in and the electrical method records the same MC as the calculation based on the X-ray CT method. After that, the electrical MC corresponds with the MC of the earlywood layer at the bottom of the electrodes. The electrical MC is thus much higher than the average MC of ROI measured by X-ray CT method (Fig.12a). Overall, the electrical MC measurement method is 
suitable for measuring the MC distribution in plywood thanks to its layered structure. Although the electrical MC can be higher than the average MC of a veneer, this method can effectively monitor the maximum MC of this veneer, which can play a key role in assessing its influence on strength properties as well as potential decay.
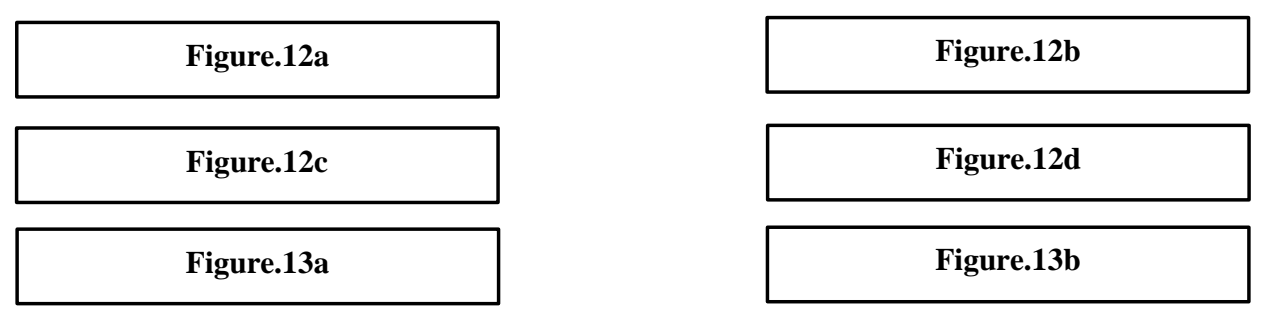

\subsection{MC of oriented strand board}

Oriented strand board (OSB) is a wood-based panel made from strands of wood bonded together with a binder under pressure and heat. The strands in the core layer can be randomly oriented, or aligned. Its internal structure is more complex than solid wood and plywood panels. As illustrated in Fig.14a, the MC measured by both electrical and X-ray CT method is less than $15 \%$, which indicates little water can penetrate across $8 \mathrm{~mm}$ thick OSB after 16 days immersion because presence of paraffin wax can increase hydrophobicity of OSB. Fig.14b also shows that there is a good agreement between these two MC measurement methods when the MC is below 20\%. However, the electrical MC differs from X-ray MC in the last two measurements. As is well known, the glue distribution in each "layer" of OSB is not equal, causing an uneven water distribution. Because the uneven glue distribution, water will probably move at a different speed. If there is sufficient water between the electrodes and only little water close to the electrodes, a higher electrical resistance and thus a lower MC would be recorded than expected. On the contrary, if both electrodes are in contact with a volume with high MC, the electricity could follow the path of least resistance instead of the ROI of interest. The electrical MC would then be higher than the actual MC of the ROI. This hypothesis is visually supported by Fig. 15 in which the water is concentrated under the dashed line. It is obvious that the water distribution near these two electrodes can differ considerably. In Fig.15a, there is little water around the right electrode, in Fig.15b both electrodes are actually in contact with water. The electrical MC, therefore, is smaller than X-ray MC at 336 hours measurement and higher than X-ray MC at 384 hours measurement. Overall, the electrical MC measurement method could be used in testing the MC of OSB if the water distribution is not important, but best in combination with X-ray CT scanning.
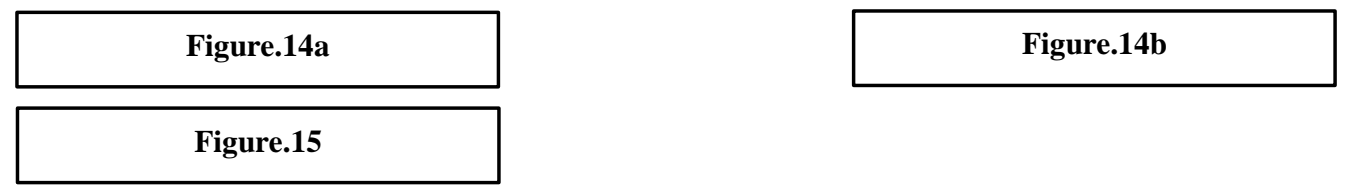

The above results give evidence that the MC distribution is different between the various wood-based products. Relating these findings to issues of physical and biological degradation that can arise, the more appropriate material can be selected for in-service outdoor conditions. Furthermore, the knowledge of MC distribution in various regions of the wood material can help us optimize the architectural design and protection against decay. To continuously record the MC distribution using the electrical method under inservice conditions, a combination with other measurement methods is most useful. For example, CMM (continuous moisture measurement) and a weather station can be used to record the average MC of the specimens and all possible weather information[3]. As such the data recorded by the electrical method can be further optimized e.g. selecting the data recorded at the time with stable average MC and no rain. The average MC and MC distribution can also help us to decide the most appropriate time to scan the specimens with X-ray $\mathrm{CT}$ in order to obtain the 3D density and moisture distribution.

\section{Conclusion}

The X-ray CT method presented here can accurately measure the MC and its distribution of wood and wood-based products. The electrical MC measurement method in its turn is an efficient approach to continuously monitor the moisture distribution of wood and wood-based products. This method can be used to measure the MC between the two electrodes if the MC is evenly distributed in this region. If not, it is difficult to reveal the actual MC of this region. To optimize this method, the microstructure and the position of the electrodes should be analyzed and checked carefully using X-ray CT scanning during set-up. More 
precisely, the density distribution between the two electrodes plays a crucial role in the performance of the electrical MC measurement method on solid wood. The study shows that wood species with a uniform density distribution and especially plywood panels are very suitable to use this method. X-ray CT method is anyhow a necessary complementary technique if full moisture analysis is aimed at. This way, the position of the electrodes can be checked and the reliability of the recorded data can be analyzed, as well as interpreted correctly in function of the structure. Furthermore, accurate water distribution can be mapped and visualized non-destructively in addition to electrical MC measurements.

In this research, the controlled laboratory conditions are designed based on the practical dynamic outdoor conditions with moisture absorption and desorption. In future research, the electrical MC measurement method, combined with periodically X-ray tomography scanning, will be used to continuously monitor the MC distribution of wood specimens exposed outdoors. In combination with a set-up such as CMM and weather station, the optimal recording and scan timing can be chosen. To measure the MC distribution more accurately using the electrical resistance method, the formula to convert resistance to $\mathrm{MC}$ will be adjusted in terms of the wood species specific resistance characteristics. In addition, the MC distribution will be used to assess decay risk. To optimize these MC measurement methods, new scan and reconstruction methods will be elaborated on to reduce metal artefacts. Also image processing software will be used to correct for dimensional changes (semi-)automatically.

\section{Acknowledgement}

The authors would like to thank Mr. Rik De Rycke and Mr. Stijn Willen for their technical assistance. The authors also would like to thank the fund from the China Scholarship Council (CSC) for the PhD funding granted to the first author. The Special Research Fund of the Ghent University (BOF) is acknowledged for the doctoral grant to Loes Brabant. This research was performed in support of the European Projects PerformWood "Performance standards for wood in construction - delivering customer service life needs", with project number 319132 and SILEX "Improving sustainability of construction materials using innovative silicon-based treatment", with project number LIFE11 ENV/BE/1046. 


\section{References}

[1] Walker JCF. Primary wood processing : principles and practice. 1st ed. London ; New York: Chapman \& Hall; 1993.

[2] Gerhards CC. Effect of Moisture-Content and Temperature on the Mechanical-Properties of Wood - an Analysis of Immediate Effects. Wood Fiber Sci. 1982;14:4-36.

[3] Van den Bulcke J, Van Acker J, De Smet J. An experimental set-up for real-time continuous moisture measurements of plywood exposed to outdoor climate. Building and Environment. 2009c;44:2368-77.

[4] Macindoe L, Leonard J. Moisture content in timber decking exposed to bushfire weather conditions. Fire and Materials. 2012;36:49-61.

[5] Brischke C, Rapp AO, Bayerbach R. Measurement system for long-term recording of wood moisture content with internal conductively glued electrodes. Building and Environment. 2008;43:1566-74.

[6] Brischke C, Rapp AO, Bayerbach R, Morsing N, Fynholm P, Welzbacher CR. Monitoring the "material climate" of wood to predict the potential for decay: Results from in situ measurements on buildings. Building and Environment. 2008;43:1575-82.

[7] van Houts JH, Wang SQ, Shi HP, Pan HJ, Kabalka GW. Moisture movement and thickness swelling in oriented strandboard, part 1. Analysis using nuclear magnetic resonance microimaging. Wood Science and Technology. 2004;38:617-28.

[8] Meder R, Codd SL, Franich RA, Callaghan PT, Pope JM. Observation of anisotropic water movement in Pinus radiata D. Don sapwood above fiber saturation using magnetic resonance micro-imaging. Holz Roh Werkst. 2003;61:251-6.

[9] Chen S, Liu X, Fang L, Wellwood R. Digital X-ray analysis of density distribution characteristics of wood-based panels. Wood Science and Technology. 2009;44:85-93.

[10] De Ridder M, Van den Bulcke J, Vansteenkiste D, Van Loo D, Dierick M, Masschaele B, et al. High-resolution proxies for wood density variations in Terminalia superba. Annals of botany. 2011;107:293-302.

[11] Lindgren LO. Medical Cat-Scanning - X-Ray Absorption-Coefficients, Ct-Numbers and Their Relation to Wood Density. Wood Science and Technology. 1991;25:341-9.

[12] Watanabe K, Saito Y, Avramidis S, Shida S. Non-destructive Measurement of Moisture Distribution in Wood during Drying Using Digital X-ray Microscopy. Drying Technology. 2008;26:590-5.

[13] Sandberg K, Salin J-G. Liquid water absorption in dried Norway spruce timber measured with CT scanning and viewed as a percolation process. Wood Science and Technology. 2010;46:207-19.

[14] Mannes D, Lehmann E, Cherubini P, Niemz P. Neutron imaging versus standard X-ray densitometry as method to measure treering wood density. Trees. 2007;21:605-12.

[15] Nakanishi TM, Matsubayashi M. Nondestructive water imaging by neutron beam analysis in living plants. J Plant Physiol. 1997;151:442-5.

[16] Masschaele BC, Cnudde V, Dierick M, Jacobs P, Van Hoorebeke L, Vlassenbroeck J. UGCT: New x-ray radiography and tomography facility. Nucl Instrum Meth A. 2007;580:266-9.

[17] Van den Bulcke J, Boone M, Van Acker J, Van Hoorebeke L. Three-Dimensional X-Ray Imaging and Analysis of Fungi on and in Wood. Microscopy and Microanalysis. 2009b;15:395-402.

[18] Van den Bulcke J, Boone M, Van Acker J, Stevens M, Van Hoorebeke L. X-ray tomography as a tool for detailed anatomical analysis. Ann Forest Sci. 2009a;66.

[19] Dierick M, Van Loo D, Masschaele B, Boone M, Van Hoorebeke L. A LabVIEW (R) based generic CT scanner control software platform. J X-Ray Sci Technol. 2010;18:451-61.

[20] Vlassenbroeck J, Dierick M, Masschaele B, Cnudde V, Van Hoorebeke L, Jacobs P. Software tools for quantification of X-ray microtomography at the UGCT. Nuclear Instruments and Methods in Physics Research Section A: Accelerators, Spectrometers, Detectors and Associated Equipment. 2007;580:442-5.

[21] Brabant L, Vlassenbroeck J, De Witte Y, Cnudde V, Boone MN, Dewanckele J, et al. Three-Dimensional Analysis of HighResolution X-Ray Computed Tomography Data with Morpho+. Microscopy and Microanalysis. 2011;17:252-63.

[22] Haygreen JG. Forest products and wood science an introduction. 3rd ed. Ames: Iowa State University Press; 1996.

[23] Mounji H, Bouzon J, Vergnaud JM. Modeling the Process of Absorption and Desorption of Water in 2 Dimensions (Transverse) in a Square Wood Beam. Wood Science and Technology. 1991;26:23-37.

[24] Sedighi-Gilani M, Griffa M, Mannes D, Lehmann E, Carmeliet J, Derome D. Visualization and quantification of liquid water transport in softwood by means of neutron radiography. International Journal of Heat and Mass Transfer. 2012;55:6211-21.

[25] Pang SS, Herritsch A. Physical properties of earlywood and latewood of Pinus radiata D. Don: Anisotropic shrinkage, equilibrium moisture content and fibre saturation point. Holzforschung. 2005;59:654-61. 
Table 1

The details of the wood based panels.

\begin{tabular}{cccc}
\hline Type & Wood species & \# of plies & Thickness [mm] \\
\hline Plywood & Pine & 7 & 18 \\
Plywood & Spruce & 5 & 15 \\
OSB & Spruce+Pine & - & 17 \\
\hline
\end{tabular}

Table 2

The distance between end grain face and electrodes.

\begin{tabular}{ccccccc}
\hline Wood species & Poplar & Spruce & Pine heartwood & Pine sapwood & Okoumé & Birch \\
\hline $\mathrm{X}(\mathrm{mm})$ & 40 & 20 & 10 & 40 & 10 & 35 \\
\hline
\end{tabular}

Table 3

Depth of electrodes, measured from the bottom face of the panels, in plywood and OSB.

\begin{tabular}{cccc}
\hline Panels & Pine plywood (Layer) & Spruce plywood (Layer) & OSB (mm) \\
\hline \multirow{2}{*}{ Depth } & $4^{\text {th }}$ & $2^{\text {nd }}$ & 8 \\
& $5^{\text {th }}$ & $3^{\text {rd }}$ & 3 \\
\hline
\end{tabular}

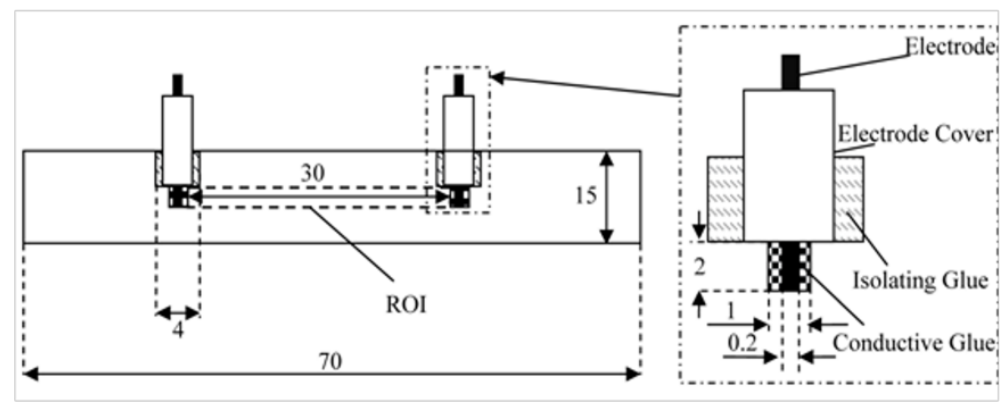

Fig.1. Detailed view of electrodes (all dimensions in $\mathrm{mm}$ ).

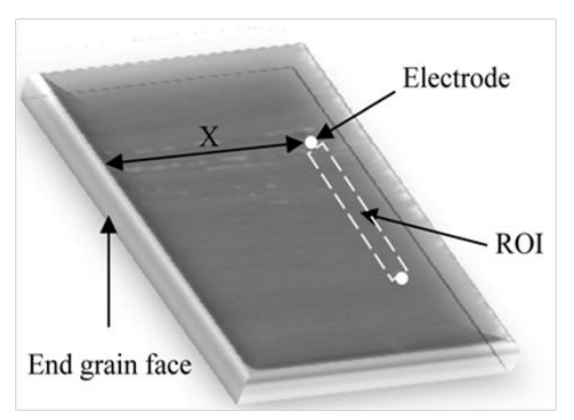

Fig.2. Overview of solid wood specimen.
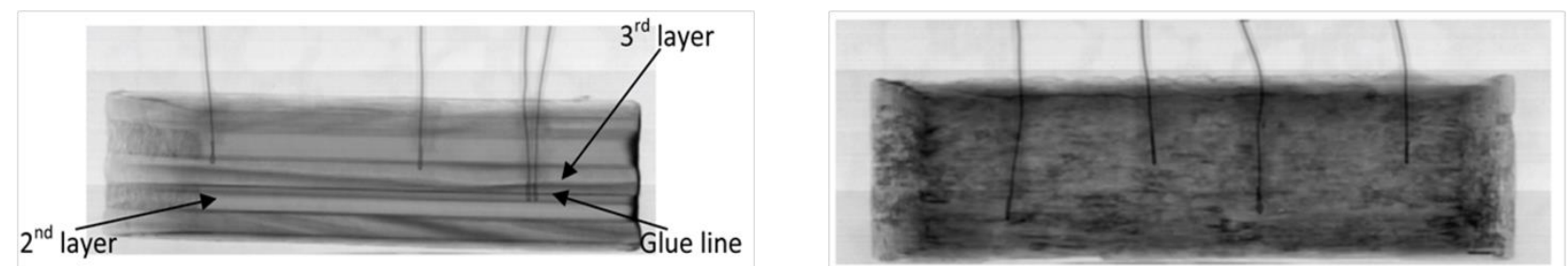

Fig.3. X-ray radiographies of electrodes in spruce plywood (left) and OSB (right). 


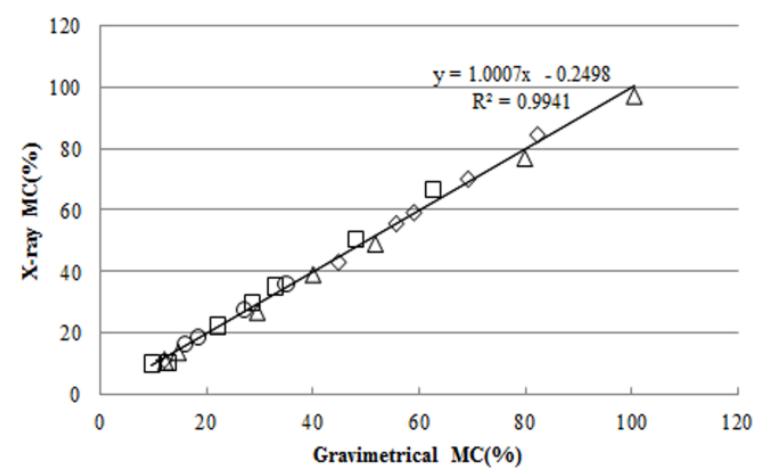

Fig.4. The relationship between the MC measured with X-ray CT and measured gravimetrically. $\square=$ birch, $\Delta=$ poplar, $O=$ pine heartwood, $\diamond=$ pine sapwood.
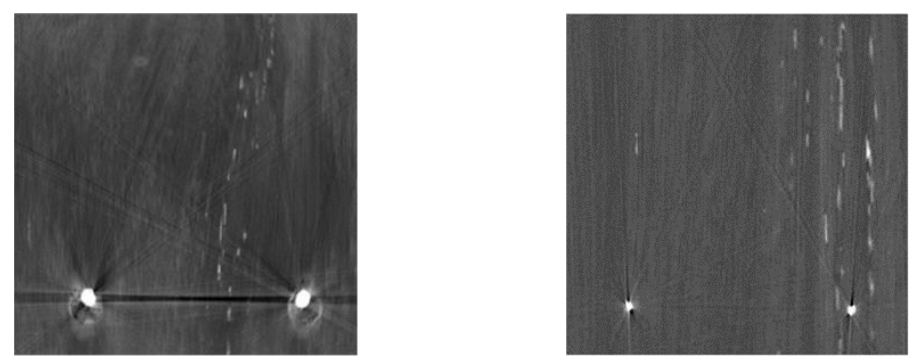

Fig.5. CT image obtained from thick wires (left) and thin wires (right).

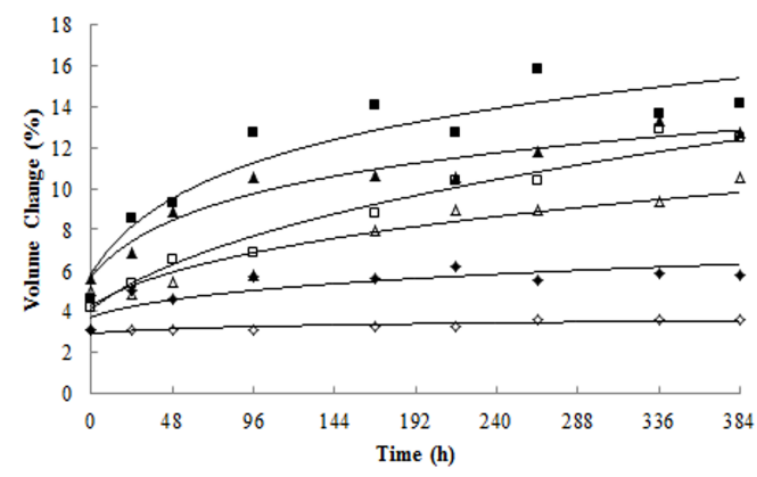

Fig.6. The volume change of the entire specimen and the ROI plywood, $\diamond=$ pine plywood ROI of $4^{\text {th }}$ layer. 


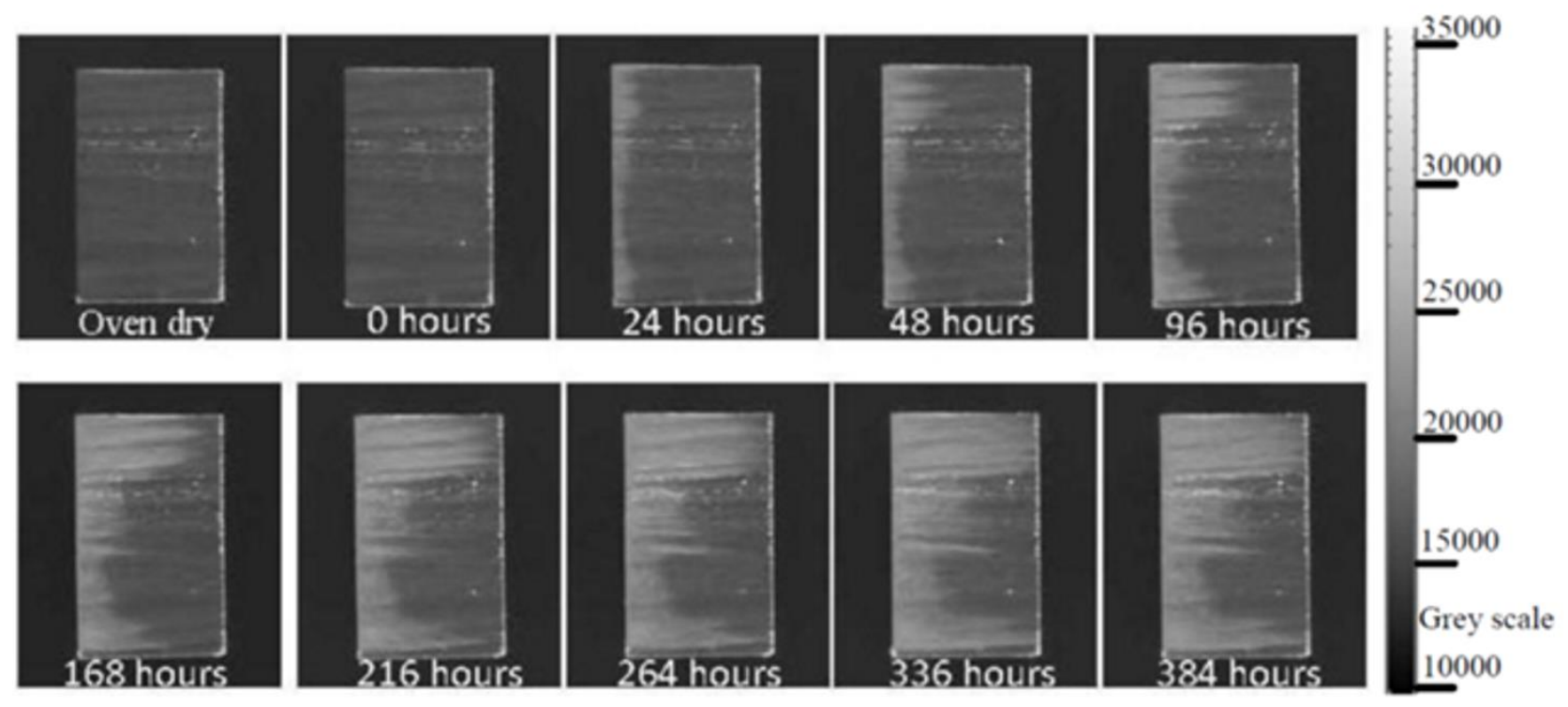

Fig.7. CT slices of water ingress in poplar after immersion.

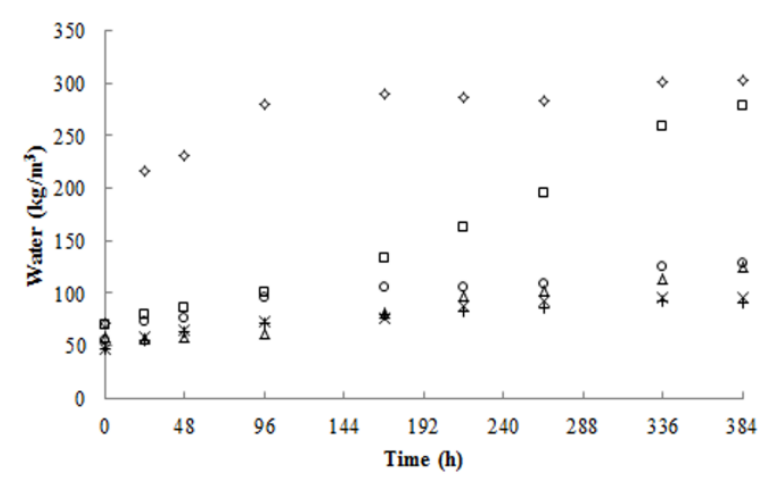

Fig.8. The amount of water in the ROI of 6 wood species. $\diamond=$ pine sapwood, $\square=$ birch, $\bigcirc=$ pine heartwood, $\Delta=$ poplar, $\times=$ spruce, $+=$ okoumé.
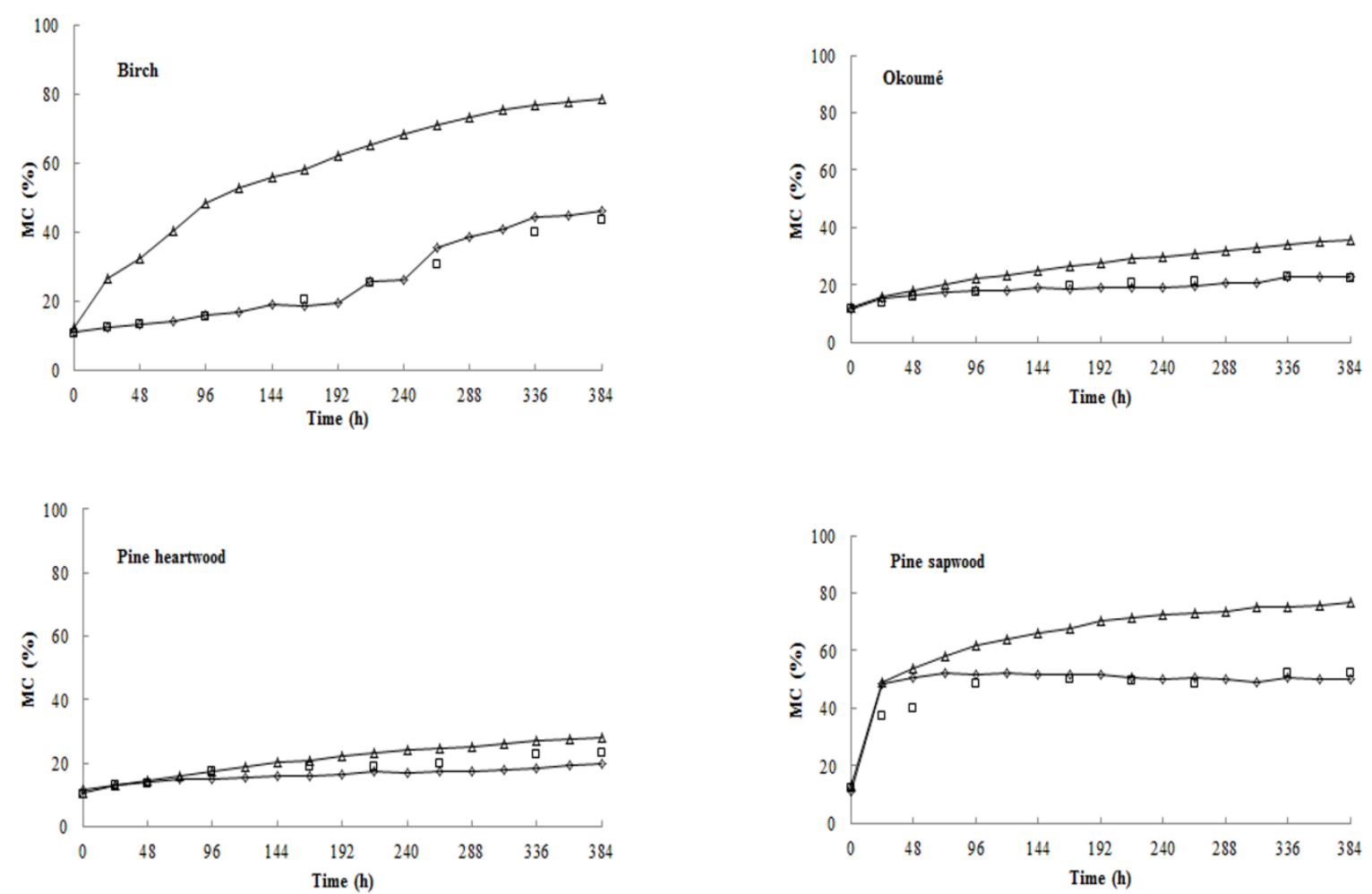

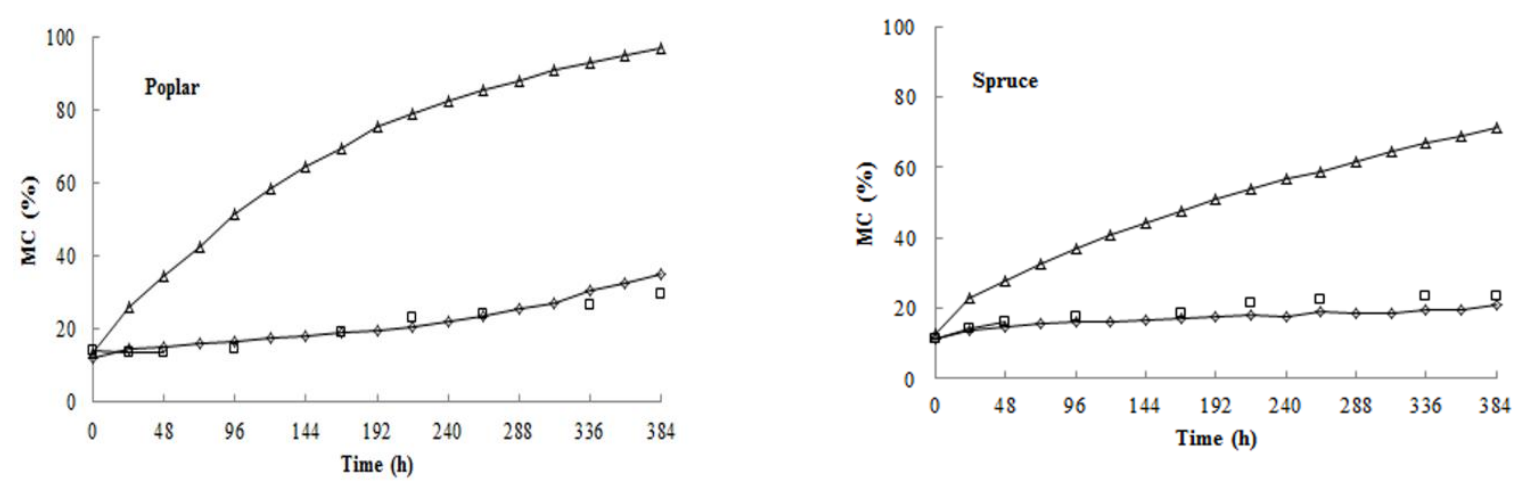

Fig.9. The MC of solid wood tested by three methods. $\diamond=$ electrical ROI MC, $\square=$ X-ray ROI MC, $\Delta=$ gravimetrical average MC

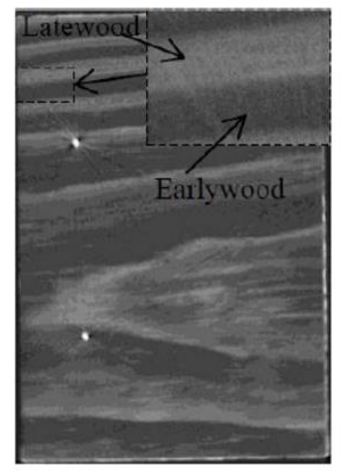

a

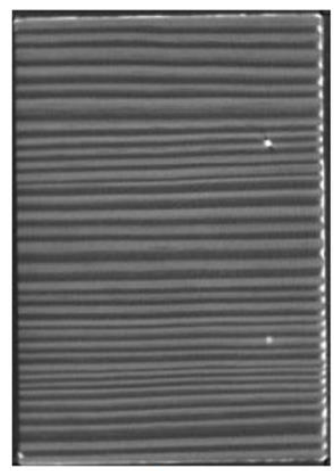

b

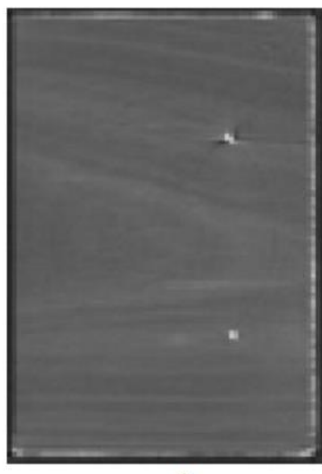

c

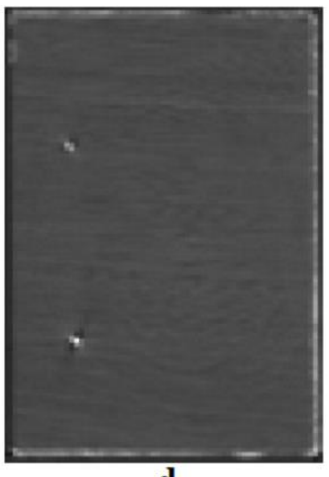

d

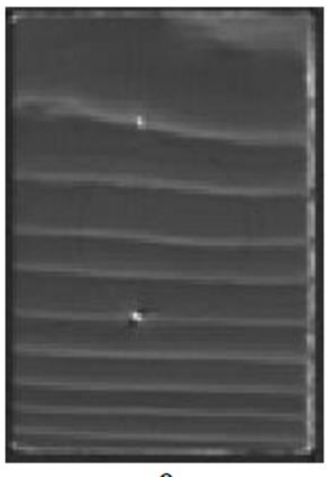

e

Fig.10.The macroscopic structure of 5 wood species: (a) pine heartwood; (b): pine sapwood; (c): birch; (d): okoumé; (e): spruce. The lighter colors represent high densities and the dark colors represent lower densities.
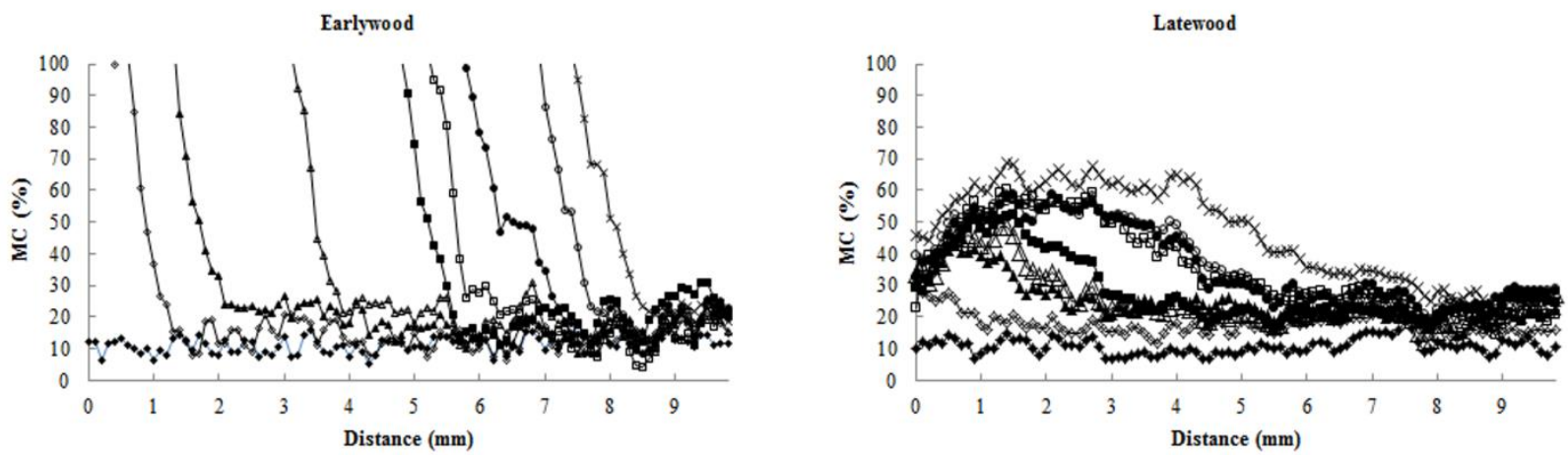

Fig.11 MC changes in earlywood and latewood of pine heartwood at different distance from the end grain face. $<=0$ hours, $\diamond=$ 24 hours, $\boldsymbol{\Delta}=48$ hours, $\Delta=96$ hours, $\boldsymbol{\square}=168$ hours, $\square=216$ hours, $\boldsymbol{O}=264$ hours, $\mathrm{O}=336$ hours, $x=384$ hours.
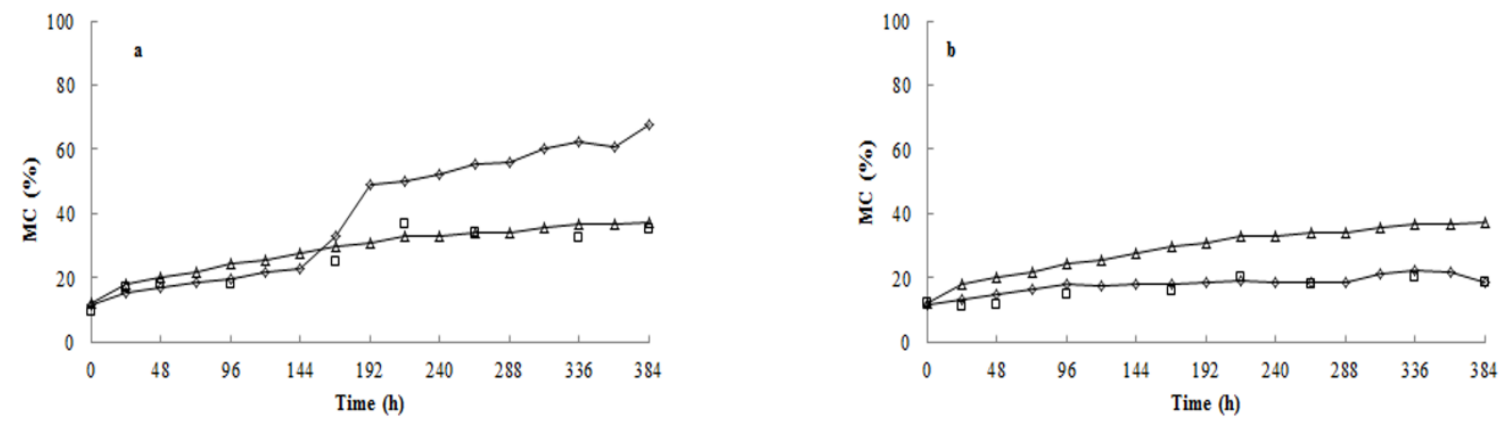

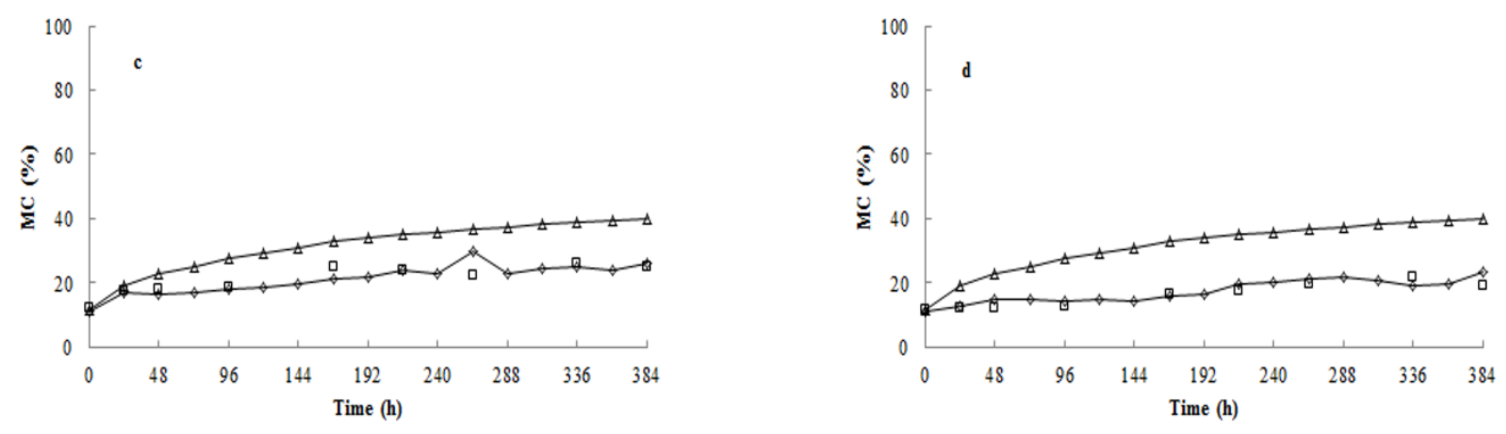

Fig.12. The MC of plywood tested by three methods. (a): the $2^{\text {nd }}$ layer of spruce plywood; (b): the $3^{\text {rd }}$ layer of spruce plywood; (c): the $4^{\text {th }}$ layer of pine plywood; (d): the $5^{\text {th }}$ layer of pine plywood. $\diamond=$ electrical ROI MC, $\square=$ X-ray ROI MC, $\Delta=$ gravimetrical average MC.
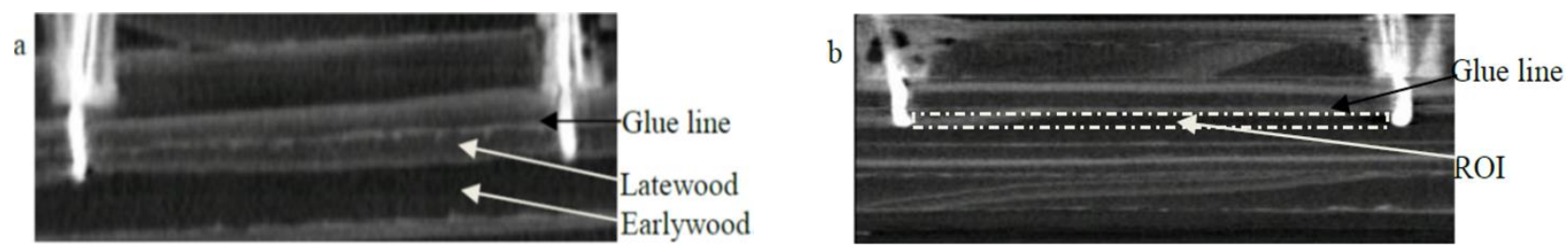

Fig.13. The internal structure of spruce plywood: (a) the $2^{\text {nd }}$ layer; (b) the $3^{\text {rd }}$ layer.
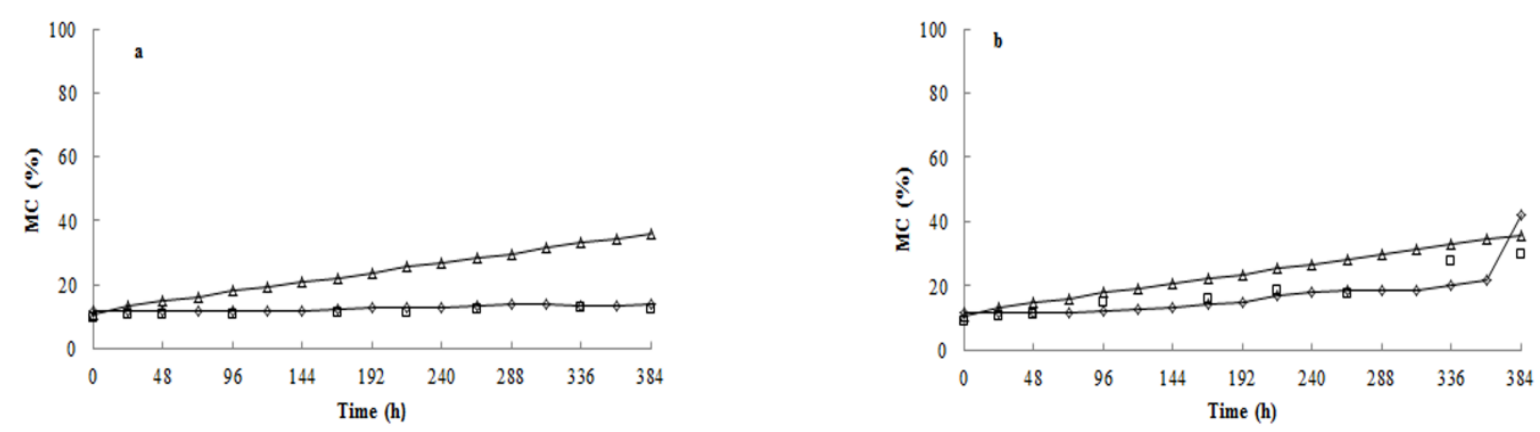

Fig.14. The MC of OSB tested by three methods. (a): the depth of $8 \mathrm{~mm}$; (b): the depth of $3 \mathrm{~mm}$. $\diamond=$ electrical ROI MC, $\square=\mathrm{X}$-ray ROI MC, $\Delta=$ gravimetrical average MC.

a
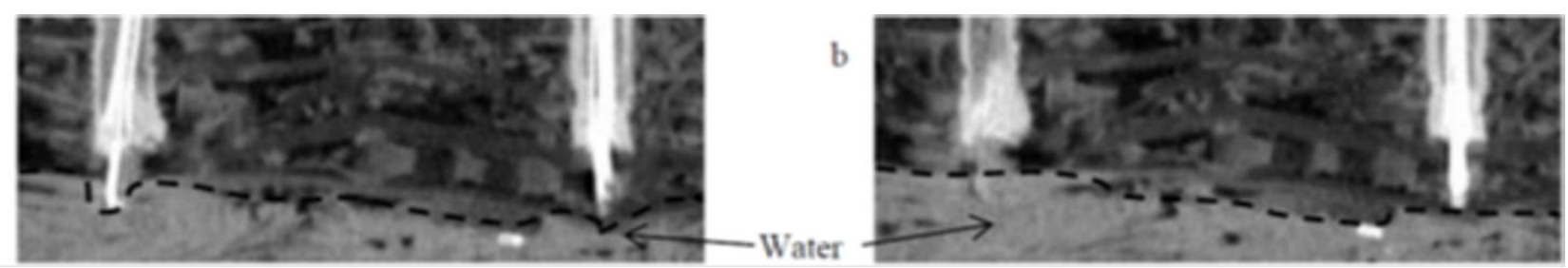

Fig.15. X-ray images of the internal structure of OSB at a depth of 3mm: (a) after 336 hours; and (b) after 384 hours of immersion. 